\title{
An Aesthetic Interpretation of Qinling's Ecological Blend Features in Tang Poems
}

\author{
Yi Zhang ${ }^{1,2 *}$ \\ ${ }^{1}$ School of Literature and Communication, Xi'an FanYi University, Xi'an, Shaanxi, China \\ ${ }^{2}$ Graduate School of Design Arts \& Culture, SangMyung University, Cheonan, South Korea \\ *Corresponding author. Email: longbowyi@163.com
}

\begin{abstract}
The Qinling Mountains are known as the dragon veins of China, and are also the central mountains that are geographically compatible with north and south, and run through the east and the west. Such natural geographic conditions determine the special ecology of the Qinling. The Qinling Mountains are located near Chang'an, the capital of the Tang Dynasty. Visitors passed through the Qinling Ancient Road very frequently, and living at the northern foot of the Qinling Mountains became a leisure fashion for the upper class in the Tang Dynasty. Such natural and humanistic conditions have promoted the prosperity of Tang poetry on Qinling theme. And these Tang poems mostly reflect that Qinling ecological landscape is compatible with that of the north, the south, the east and the west in regional features and gradual and repeated progress in seasonal features. And then, aesthetics of poetry has been formed in Tang poems.
\end{abstract}

\section{Keywords: Tang poetry, Qinling Mountains, landscape, blend, compatibility}

\section{INTRODUCTION}

Taine, a French philosopher, attached great importance to the decisive role of geographical environment and natural conditions on human civilization. The objective conditions of physical geography are the basis of all human cultural, literary and aesthetic activities. The comprehensive factors of ecological geographical environment restrict people's production, life and artistic aesthetic way. Zhongnan Mountain is the core area of Qinling Mountains, which is not only geographical but also cultural. In China's territory, Zhongnan Mountain is at the geometric center, even the geographical geometric center of the East Asia. Culturally, the concept of space in ancient Chinese culture is the concept of the universe. In "Wenzi·Ziran", "宙" refers to the time span from ancient times to the present, and "宇" refers to the east, the west, the north, the south, the heaven (up) and the earth (down). In "Shih Chi · Qinshihuang", "the world or universe is owned by the emperor."

*Funds: 2016 Xi'an social science fund planning key project "Qinling ancient road ancient poetry review"(16XF03); 2017 Shaanxi Provincial Department of Education Special Research Project "Study on the Variation of the 'Chinese Image' under the Community Consciousness in Tang Poetry"(17JK0978); The project from the fund of The research team of Xi'an FanYi University: "Literature Geography and Regional Literature Research"(XFU17KYTDD03).
Zhongnan Mountain, which is opposite to the capital of all dynasties, is the central mountain among the six directions. It also has a title of "中南 山", that is, it is in the middle of the south are to the capital. Now, the Qinling area where Zhongnan Mountain is located is known as the "National Central Park".

\section{THE COMPATIBILITY OF NORTHERN} AND SOUTHERN STYLES IS MANIFESTED IN ECOLOGICAL BLEND OF THE REGIONAL SPACE

The location and ecology of Qinling Mountains fully reflect the compatibility of "six directions" in space, that is, east-west compatibility, north-south compatibility and up-down compatibility. In terms of longitude, Zhongnan Mountain runs through the East and the West. According to Wang Wei's poem "Zhongnan Mountain", "The towering Zhongnan Mountain seems to be close to Chang'an, and the mountains stretch out to the seashore. In the east, it reaches the south of Henan Province to the Huaihai River. In the west, it passes through the Qilian mountains and Kunlun mountains to reach the Central Asia. It is the confluence pivot between the eastern and western seas and the high mountains. It reaches Chang'an, or connects with the sea level, making it an area of compatibility between heaven 
and earth. There is a poem "Honghe and Tianchi, Taibai Mountain and Zhongnan Mountain as the earth's axis" ( $\mathrm{Du} \mathrm{Mu}$ ). Throughout Tang poems on the landscape of Zhongnan Mountain, there is a wide range of materials and poets. In view of the northern and southern regional compatibility of Zhongnan Mountain ecology, this paper mainly studies the four themes.

\section{A. Works on travelling along ancient mountain roads}

Zhongnan Mountain traverses the East and West, separating the north and the south, but the ancient people opened up several ancient roads among the Qinling Mountains, connecting the north and the south of the mountains. Up to now, the main route of the outdoor crossing activities in Zhongnan Mountain is the ancient road. Qinling is close to Chang'an, the imperial capital. People who went in and out of Chang'an passed through the ancient mountain roads very frequently. Therefore, there are rich Tang poems about the theme of the ancient Qinling road. In the "Collection of poetry in the Tang Dynasty", there are nine people writing the poem with the same title of "watershed", namely, Xue Neng, Lu Zhaolin, Meng Jiao, Yuan Zhen, Bai Juyi, Li Shangyin, Xu Tang, Wu Rong and $\mathrm{Wu}$ Bin. The poets passed the ancient road "watershed" in the Qinling Mountains, feeling the compatibility between the north and the south of the Qinling Mountains and the landscape and meteorology. At the same time, the hardships on the ancient Qinling road is used to symbolize the hardships of life and official career. In "Watershed" (Yuan Zhen), "崔嵬分水岭, 高下与云平，上有分流水，东西 随势倾. 朝同一源出，暮隔千里情. 风雨各自异，波澜相背惊. " These sentences describe the height of the watershed, which is equal to the clouds, regardless of the north and the south. From the perspective of the sky, the north and the south are compatible. On the surface, they come from the same source, showing that the water system in the mountain is of the same origin, but also does not distinguish between the north and the south, and reflecting the characteristics of compatibility.

\section{B. Works on leisure}

In "Spring in the Difeishan Mountain" (Wen Tingyun), "再再花明岸，涓涓水绕山. (flowers bloom on the shores, trickling water runs around the mountains)" The two overlapping words "Ranran" ( 再再) and "Juanjuan" (涓涓) clearly describe the soft and beautiful spring scenery of Zhongnan Mountain. There are also poems about the landscape of the northland of Zhongnan Mountain, such as "Visiting Cui Jiancheng in the south of city" (Liu Deren): "门与青山近，青山复几重。雪融皇子 岸，春浥翠微峰. 地有经冬草，林无未老松. 竹寒溪隔寺，晴
日直闻钟. (The gate is close to the green hill, and the green hill is multiple. The snow melted at the Huangzi shores, the spring started at the Cuiwei peaks. There is grass survived in the winter, and there is no old pine in the forest. Bamboos exist across the temple, and the bell is heard on sunny days.) "雪融" and "春浥" show the tenderness of the southern country and strong northern colors. There are several layers of green hills and ridges, and the grass turns green again after winter, and the bamboo bushes exist by the cold stream that are separated from the temple. A spring cold peculiar to Northland is like falling into the sleeves. With a clear day in the cold spring, and the clear bells can be heard, perhaps it will gradually be a warmer spring in the northern country in the middle of the day.

\section{Works on seclusion}

According to Wang Wei's "Shimen in Lantian Mountain"，"道心及牧童，世事问樵客.暝宿长林下，焚香 卧瑶席." This poem expresses the temperament and interest of reclusion. Also, there are poems of the Qinling mountains that are compatible with the scenery of the north and the south, such as "落日山水 好，漾舟信归风", expressing the southern artistic conception, and "山月映石壁", reflecting the scenery of mountain in the north. Meng Haoran's reclusive poem "on the empty room at Cuiwei temple in Zhongnan Mountain" describes the beauty of seclusion and the natural landscape of Qinling Mountains, which has the "Chicheng landmark" and "linhaiqiao" of the mountains and rivers of eastern Zhejiang.

\section{Works on seeking the true meaning of life}

In Li Duan's "searching for Liu Chushi in late spring", the author visited Liu Chushi and obtained the truth of life that "there are foreign affairs occasionally, and I have a simple heart. And the spring traveler are boring, there is the same for the years of sorrow. (偶来尘外事，暂与素心期.终恨游春客， 同为岁月悲)" At the same time, there are sentences expressing the leisure and freedom in the background of landscape and pastoral, such as "the flower path into the stream is far away, and the bird to the mountain is late. Purple Pueraria weeps moss wall, green mushroom mirrors willow silk. (入溪花 径远，向岭鸟行迟. 紫葛垂苔壁，青菰映柳丝.)". It can be seen that the soft and beautiful sentiment of the flower path beside the stream, the moss wall of purple Pueraria and the willow silk, and the magnificent beauty of the mountain. It embodies the natural ecology of northern and southern compatibility. Lv Wen's poem "hearing the sound in Zhongnan Mountain at the middle of month" also expresses the feeling of being out of the world, 
rejecting the crowd and seeking the liberation of life. The poem also uses "月峰" (peak), "幽船" (big mountain stone), "泠泠" (clear), "查查" (distant) and "寒云" (cloud) to express the tranquility of Zhongnan Mountain in the night.

\section{SEASONAL ECOLOGICAL BLEND}

Qinling Mountains are not only the border between the north and the south of China, but also the transition zone between the East and the West. The location in the middle of the East, West, North and south makes the standard of seasonal changes around the Qinling Mountains the most balanced and can take care of the whole country. Therefore, China's geodetic origin and the national time service center are located within tens of kilometers around the Qinling Mountains. Therefore, in the cycle of the four seasons, the seasonal changes of Qinling Mountains are the most abundant. They are not only distinct in four seasons, but also present the characteristics of gradual and repeated reversion when the four seasons change. This seasonal change brings people a very rich and changeable feeling. In order to better identify the seasons and serve the farming, the developed calendar system in the Central Plains area of ancient China was formed. Therefore, it became an important duty of ancient officials to ensure that the people did not violate agriculture in their production and life. The following is the characteristics of the four seasons blend in the Qinling Mountains reflected in Tang poetry.

\section{A. The scenery change in winter and spring}

The change of this season has special significance and style. On the one hand, it is natural; on the other hand, it is humanistic. From the natural point of view, the alternation of winter and spring contains people's eagerness for spring flowers to bloom in the test of a cold winter. Especially after the beginning of spring, there is often cold spell in later spring, which makes spring more valuable and increases people's deep feelings for the alternation of winter and spring. From the humanistic point of view, the alternation of winter and spring also has the cultural significance. People bid farewell to the old and usher in the new. Spring is a symbol of a better future, and winter becomes the test before the arrival of the good. Moreover, the alternation of the two makes the alternation of winter and spring a cultural symbol of the course of life. The poems of the Tang Dynasty often showed the situation that the imperial examinations were released in the spring. Thousands of candidate for the imperial examinations swabbed eyes and looked forward to the success of his life on the release day, but they were very worried about failing in official examination, which is like the cold weather in the late spring. This specific situation is similar to the alternation of winter and spring. In $\mathrm{Zu}$ Yong's poem "Viewing snow at Zhongnan Mountain", "终南阴岭 秀，积雪浮云端.林表明雯色，城中增暮寒." 林表明雯色，城 中增暮寒." It shows the imperial examination at the turn of winter and spring and the subtle expression of the future of life. There are also poems, such as $\mathrm{Li}$ Ziqing's "looking at the spring snow in Zhongnan Mountain", Zhang Qiao's "Zhongnan Mountain", Bai Juyi's "early spring in the stream", and Liu Deren's "traveling to the south".

\section{B. The scenery change in spring and summer}

The seasonal changes in spring and summer in Zhongnan Mountains are the most natural. From spring to summer, the weather gradually becomes slightly hot. Inadvertently, it moves towards the prosperous time of rainy and hundred valleys. After the beginning of summer, the climate has been repeated, but it is no longer too cold to be unbearable. Although there are some works on the cold spring and the passage of time, the chill is difficult to reduce the gradually rising temperature, but it is more the restlessness of early summer and the exuberance of life. The same is true of the climate changes in Zhongnan Mountain in spring and summer. At the beginning of the poem "To Bai Juyi", "城外园林初夏天" shows the wild interest of the garden under the Zhongnan mountain. "乱" of " 萻薇乱发多临水" places that kind of unrestrained freedom in the wild interest of wild rose flowers. According to "水底远山云似雪，桥边平岸草如烟", the vision is enlarged to distant mountains and flat banks. The reflection of white clouds on the distant mountains is like snow, and the grass on the flat bank is like smoke. It is fresh and verdant. It seems that spring is still lingering, which makes people feel refreshed and happy. There are poems such as Bai Juyi's "He Chaohui and Wang Lianshi travel under the Zhongnan Mountain", Yang Shidao's "Zhongnan Mountain rhyme", Jia Dao's "Viewing Zhongnan Mountain", etc.

\section{The scenery change in summer and autumn}

In summer and autumn, the scenery change of Zhongnan Mountain also goes on and develops gradually. The bleak of autumn does not appear immediately, but slowly comes out after repeated competitions with the heat of summer. It's just as impressive as the alternation of winter and spring. In "Viewing Zhongnan Mountain", "日爱南山好，时 逢夏景残. 白云兼似雪，清昼乍生寒. 九陌峰如坠，千门翠可 团. 欲知形胜尽，都在紫宸看." The application of the opening, developing, changing and concluding is natural and smooth. The first and second sentences play the role of opening. The reasons, time and objects are given. The beauty of Zhongnan 
Mountain is in the heart of people every day. At this time, the poet looked at beloved Zhongnan Mountain. It's the end of summer and the beginning of autumn. The third and fourth sentences play the role of developing. The summer scenery of Zhongnan Mountain is described. The white clouds in the mountains are not flowing, which makes the cold day suddenly produce a chill. At the end of summer, the poet felt a sense of cool autumn. The fifth and sixth sentences play the role of changing. From the "Zichen" point of view, Zhongnan mountain is high and cool in the early autumn. The mountain peak is as high as falling from the sky. The mountain color is rich and green in the late summer and early autumn. The green color and freshness at the turn of summer and autumn are extreme. There are also poems such as Zhang Jiuling's "Viewing Zhongnan Mountain", Wang Wei's "To Pei Di".

\section{The scenery change in autumn and winter}

The scenery change in autumn and winter is the most unforgettable. All prosperity is coming to an end, as if the life cycle of a dying moment. Winter is the end of a year. The chill of autumn appears. At this time, people still feel regret for the time that has just passed, or they are waiting for the winter to clean up a mess and look forward to the beginning of the next life cycle. "Autumn snow in Zhongnan Mountain" and "watching autumn snow in Zhongnan Mountain with Liu" are two poems written by Liu Yuxi and Bai Juyi. In Bai's poem, the anthropomorphic technique is used to describe the phenological characteristics of autumn and winter. The autumn grass is surprised by the heavy frost brought by the autumn snow. The pine doubts that the frost and snow are so heavy, and the crane birds have not yet scattered to escape the cold ("草 讶霜凝重，松疑鹤散迟"). This is a portrayal of the weather and climate of the early cold wave at the end of autumn. In Liu Yuxi's "autumn snow in Zhongnan Mountain", it can be seen that the cold wave arrived in Chang'an City early. There was no snow in the city, but the Qinling Mountains outside the city were covered with snow (南岭见秋雪，千门生 早寒), which is called "autumn snow". There are also poems such as Chang Gun's "The memory of Zhongnan Mountain", Jia Dao's "Seeing Zhongnan snow".

\section{Conclusion}

The ecological landscape of Qinling Mountains in Tang Dynasty is very rich in Tang poetry. This is determined by the geographical conditions of Qinling Mountains and its cultural advantages close to Chang'an, the imperial capital. Although Qinling Mountains are high, there are several ancient roads leading from Chang'an to the southeast and southwest. The melancholy and loneliness on the ancient roads and the rich and colorful ecology in the mountains are the two basic thinking dimensions of the Tang poetry of Qinling Mountains. The valley at the northern foot of Qinling Mountains and the Chuanyuan near Chang'an form the upper class of social leisure. As a result, it has become the scenery that poets pay attention to. These poems reflect the ecological features of Qinling Mountains in varying degrees, with the characteristics of compatibility between the north and the south and the gradual blend of seasons.

\section{References}

[1] Hang Jie, Zhang Yi, etc. "Tang Poems on Zhongnan Mountain" [M], Xi'an: Northwest University Press, 2013. (in Chinese)

[2] Li Zhihui. "An Introduction to Zhongnan Culture" [M], Xi'an: Northwest University Press, 2017. (in Chinese)

[3] Zhang Yi et al. "Shaanxi Ecotourism" [M], Xi'an: Shaanxi People's Publishing House, 2019. (in Chinese)

[4] Bai Juncai. "Tang Poetry and Chang'an Culture" [M], Beijing: Higher Education Press, 2019. (in Chinese)

[5] Li Hao. "A Textual Research on Gardens in the Tang Dynasty" [M], Shanghai: Shanghai Ancient Books Publishing House, 2005. (in Chinese)

[6] Wang Zhiqing. "Ecological Poetics of the Prosperous Tang Dynasty" [M], Beijing: Peking University Press, 2005. (in Chinese) 